\title{
Alburnus caeruleus (Heckel, 1843) türünün Bazı Populasyon Dinamiği Parametreleri, Merzimen Çayı, Fırat Havzası, Türkiye

\author{
Burak SEÇER ${ }^{1}$, Erdoğan ÇİÇEK ${ }^{2}$, Yasemin CELEPOĞLU \\ Nevşehir Hacı Bektaş Veli Üniversitesi, Fen Edebiyat Fakültesi, Biyoloji Bölümü, 50300 Nevşehir \\ ${ }^{1}$ https://orcid.org/0000-0002-8763-131X, ${ }^{2}$ https://orcid.org/0000-0002-5334-5737, ${ }^{3}$ https://orcid.org/0000-0001-8696-4406 \\ $\bowtie$ : erdogancicek@nevsehir.edu.tr
}

\section{ÖZET}

Bu çalışmada 2013 yılında Merzimen Çayından örneklenen Alburnus caeruleus bireylerine ait populasyon dinamiği parametreleri belirlenmiştir. Toplam olarak 347 birey incelenmiş olup yaşlarının 0III yaş grupları arasında değişim gösterdiği, en baskın II. yaş grubunun (\%44.45) olduğu ve bunu sırayla I., III. ve 0. yaş gruplarının izlediği belirlenmiştir. İncelenen bireylerin $2,6-8,4 \mathrm{~cm}$ boy ve $0,11^{-}$ $6,82 \mathrm{~g}$ ağırlık dağılımına sahip olduğu ve ortalama boy ve ağırlık değerleri ise sirasiyla $5,53 \pm 1,12 \mathrm{~cm}$ ve $1,83 \pm 1,23 \mathrm{~g}$ olarak hesaplanmıştır. Merzimen populasyonuna ait boy-ağırlık ilişkisi $\mathrm{W}=0,0062 * \mathrm{TL} 3,2205$ olarak bulunmuştur. von Bertalanffy büyüme parametreleri ise $\mathrm{L} \infty: 10,50 \mathrm{~cm}, \mathrm{k}: 0,3665$, to: $-0,89$, Büyüme katsayısı $\Phi$ ': 3,7 ve Kondisyon Faktörü ise K: 0,37 bulunmuştur. Toplam, doğal ve balıkçılık nedeniyle meydana gelen ölüm oranları ile stoktan yararlanma düzeyi $\mathrm{Z}: 0,79, \mathrm{M}: 0,55, \mathrm{~F}: 0,24$ ve $\mathrm{E}: 0,30$ olarak hesaplanmıştır.

\section{Araştırma Makalesi}

\author{
Makale Tarihçesi \\ Geliş Tarihi : 25.03 .2020 \\ Kabul Tarihi : 09.04.2020
}

Anahtar Kelimeler

Büyüme

Gaziantep

Ölüm oranları

Yaş

\section{Determination of Some Population Parameters of Alburnus caeruleus (Heckel, 1843) from Merzimen} Stream, Euphrates Basin, Turkey

\begin{abstract}
The aim of this study was to determine the population parameters of Alburnus caeruleus in the Merzimen Stream, Euphrates Basin. A total of 347 specimens were analyzed the age varied from 0 -III and the majority of them are II. age (44.45\%) followed by I., III. and 0 age classes, respectively. Total length ranged from 2.6 to $8.4 \mathrm{~cm}$ and weight varied from 0.11 to $6.82 \mathrm{~g}$, and the average length and weight were calculated as $5.53 \pm 1.12 \mathrm{~cm}$ and $1.83 \pm 1.23 \mathrm{~g}$, respectively. The lengthweight relationship was expressed as $\mathrm{W}=0.0062 * \mathrm{TL} 3.221$. The von Bertalanffy growth parameters were found as Lo: $10.50 \mathrm{~cm}, \mathrm{k}: 0.3665$ and to: -0.89 , growth coefficient was $\Phi^{\prime}: 3.7$ and condition factor was $\mathrm{K}: 0.37$. Total, natural and fishing mortalities rates and exploitation rate were estimated as $\mathrm{Z}: 0.79, \mathrm{M}: 0.55, \mathrm{~F}: 0.24$ and $\mathrm{E}: 0.30$, respectively.
\end{abstract}

Research Article

$\begin{array}{ll}\text { Article History } & \\ \text { Received } & : 25.03 .2020 \\ \text { Accepted } & : 09.04 .2020\end{array}$

Keywords
Age
Mortality date
Gaziantep
Growth

To Cite: Seçer B, Çiçek E, Celepoğlu Y 2020. Alburnus caeruleus (Heckel, 1843) türünün Bazı Populasyon Dinamiği Parametreleri, Merzimen Çayı, Fırat Havzası, Türkiye. KSÜ Tarım ve Doğa Derg 23 (5): 1240-1244. DOI: 10.18016/ksutarimdoga.vi.693813.

\section{GİİŞ}

Firat Havzası hem kapladığı alan ve hem de su potansiyeli bakımından Türkiye'nin en büyük havzasıdır. Havza barındırdığı tür sayısı bakımından da zengin bir biyoçeşitliliğe sahiptir. Şu ana kadar verilen kayıtlara göre havzada 80 civarında türün dağılım gösterdiği rapor edilmektedir (Çiçek ve ark., 2015; Kara ve Alp, 2016; Kaya ve ark., 2016).

Alburnus cinsine mensup türler çoğunlukla Anadolu, Suriye, Kafkasya, Avrupa ve İan'da dağılım göstermektedir (Kottelat ve Freyhof, 2007). Türkiye'de şu ana kadar Alburnus cinsine ait 29 tür kaydı verilmiş olup bunlardan 18 tanesi endemik olarak bildirilmiştir (Çiçek ve ark., 2015; Çiçek ve ark., 2018; Freyhof ve Turan, 2019). Alburnus cinsi, parlak görünüşlü ve açık renkli vücuda, yeşilimsi esmer sırta, gümüş beyazı yan taraflara ve karın bölgesine sahiptir. Göllerde, nehirlerin hızlı akan ve su filmine yakın olan alanlarında sürüler halinde yaşarlar (Geldiay ve Balık, 2007). Alburnus caeruleus türü Dicle-Firat havzasına endemik bir tür olup $A$. sellalile simpatrik olarak Türkiye, Suriye, İran ve Irak’ta geniş 
bir dağılım alanına sahiptir (Coad, 2010, 2020; Zareian ve ark., 2015; Birecikligil ve ark., 2017; Esmaeili ve ark., 2018). Ünlü ve Bilgin (1987) ülkemizde Şanlıurfa Balıklı göl'den söz konusu türün ilk kaydını vermiştir. Fuziform yapıya sahip olan Alburnus türleri içerisinde yanlardan basık vücut yapısı vücudun tamamında bulunan siyah lekelerle kolaylıklar ayrılabilmektedir.

Popülasyon dinamiği parametrelerinin belirlenmesi balık popülasyonlarında boy, ağırlık, yaş, büyüme, ölüm gibi popülasyon üzerinde değerlendirmenin yapılmasıyla stoktan faydalanma, avcılı̆̆ın sürdürülebilirliğini sağlayarak koruma yöntemlerinin alınması için büyük bir öneme sahiptir (Sarıhan ve ark., 2007). Türkiye'de daha önce üzerinde herhangi bir çalışmaya rastlanmamış olan $A$. caeruleus türünün bu çalışma ile bazı popülasyon dinamiği parametreleri ve ölüm oranlarının belirlenmesi amaçlanmıştır.

\section{MATERYAL ve YÖNTEM}

$\mathrm{Bu}$ çalışma materyali Nisan-Kasım 2013 tarihleri arasında Merzimen Çayından (Yavuzeli, Gaziantep) örneklenmiştir. Örnekler elektroşoker kullanılarak (SAMUS 725 MP) avlandiktan sonra \%20'lik formaldehit çözeltisi ile tespit ettikten sonra \%4'lük formaldehit çözeltisinin bulunduğu bidonlar içerisinde muhafaza edilerek Nevşehir Hacı Bektaş Veli Üniversitesi İhtiyoloji laboratuvarına getirilmiştir. Laboratuvarda örneklere ait boy ölçümleri $1 \mathrm{~mm}$ hassasiyetle ve total ağırlık ise $0.01 \mathrm{~g}$ hassasiyetli elektronik terazi ile belirlenmiştir. Bireysel yaş tayini balıkların solungaç kapaklarının gerisinden alınan pulların stereo mikroskop altında yaş halkalarının sayımı ile yapılmıştır.

Boy-ağırlık ilişkisi regresyon analizi ile belirlenerek $W=a L^{b}$ eşitliği kullanılarak ifade edilmiştir. Bu eşitlikte; $W$. ağırlık (g), a ve $b$ : regresyon sabitleri ve $L$ : tam boyu (cm) göstermektedir (Sparre ve Venema, 1998).

von Bertalanffy büyüme sabitleri $L_{t}=L_{\infty}\left[1-e^{-k(t-t o)}\right]$ ve $W_{t}=W_{\infty}\left[1-e^{-k(t-t o)}\right]$ ile ifade edilmiştir. Bu eşitlikte; Lt: $\mathrm{t}$ yaştaki balığın boyu $(\mathrm{cm}), L_{\infty}$ : sonuşmaz uzunluğu $(\mathrm{cm}), W_{\infty}$ : sonuşmaz ağırlık (g), $k$ : Brody'nin büyüme katsayısı (yıl-1) ve $t_{o}$ : balığın boyunun 0 olduğu andaki kuramsal yaşını (yıl) ifade etmektedir (Sparre ve Venema, 1998). Munro'nun Fi Üssü $\Phi=\ln k+2 \ln L_{\infty}$ eşitliği kullanılarak belirlenmiştir. (Pauly ve Munro, 1984). Fulton'un Kondisyon Faktörü $K=100 \frac{\mathrm{W}}{L^{b}}$ eşitliği yardımı ile tahmin edilmiştir. (Sparre ve Venema, 1998).

Toplam ölüm oranının ( $Z$ ) hesaplanmasında Beverton ve Holt (1957) tarafindan önerilen ortalama boy değeri kullanılmıştır: $Z=k \frac{\left(L_{\infty}-\bar{L}\right)}{\left(\bar{L}-L^{\prime}\right)}$, bu eşitlikte; $\bar{L}$ : incelenen bireylerin ortalama boyu (cm), L': incelenen bireylerden en küçük boylu balıkların bulunduğu sınıf aralığını (cm) göstermektedir. Doğal nedenlerle meydana gelen ölüm oranı ( $M$ ) Pauly (1980) tarafindan geliştirilmiş olan deneysel formülden yararlanılmıştır: $\log 10 M=-0.0152-0.279 \log 10 L_{\infty}+0.6543 \log 10 \mathrm{k}+0.463 \log 10 \mathrm{~T}$.

$\mathrm{Bu}$ eşitlikte; $T$. incelenen popülasyonun yaşadığ ortamin yıllık ortalama su sicaklığını ( $\left.{ }^{\circ} \mathrm{C}\right)$ göstermektedir. Yukarıdaki eşitlikte ihtiyaç duyulan $T$ değeri Merzimen Çayı için $16,0^{\circ} \mathrm{C}$ olarak kabul edilmiştir. Balıkçılık nedeniyle meydana gelen ölüm oranı (F) ise $F=Z-M$ eşitliği kullanılarak hesaplanmıştır.

Sömürülme oranı $(E)$ ise $E=\frac{F}{Z}$ eşitliği yardımı ile belirlenmiştir (Sparre ve Venema, 1998).

\section{BULGULAR ve TARTIŞMA}

Çalışma kapsamında 347 birey örneklenmiş olup yaş, boy ve ağırlık değerlerinin değişim aralıkları ve bunların ortalama değerleri hesaplanmıştır. Buna göre popülasyondaki bireylerin yaşlarının 0-III yaş grupları arasında değiştiği belirtilmiştir (Çizelge 1). Popülasyonda baskın olan yaş \%44.45'lik oran ile II. yaş grubu olup bunu \%42.46 ile I. ve \%10.39 ile 3. yaş grupları takip etmekte olup en düşük oranın 0. yaş grubu (\%2.72) olduğu belirlenmiştir.

Çizelge 1. Alburnus caeruleus popülasyonunda yaş-boy ve yaş־ağırlık frekans dağılımları, her yaş grubuna ait ortalama boy

Table 1. Age-lenght and age-weight frequency distributions in Alburnus caeruleus population, average height for each age group

\begin{tabular}{|c|c|c|c|c|c|c|}
\hline \multirow[b]{2}{*}{$\begin{array}{l}\text { Yaş } \\
(\text { Age })\end{array}$} & \multirow[b]{2}{*}{$\mathrm{n}$} & \multirow[b]{2}{*}{$\%$} & \multicolumn{2}{|c|}{ Total Boy $(\mathrm{cm})($ Total Lenght $(\mathrm{cm}))$} & \multicolumn{2}{|c|}{ Total Ağırlık (g) (Total Weight (g)) } \\
\hline & & & $\begin{array}{l}\text { Değişim Aralığ } 1 \\
\text { (Range) }\end{array}$ & $\begin{array}{c}\text { Ortalama } \\
\text { (Mean) }\end{array}$ & $\begin{array}{l}\text { Değişim Aralığ } \\
\text { (Range) }\end{array}$ & Ortalama (Mean) \\
\hline 0 & 7 & 3.7 & $2.6-3.3$ & $2.94 \pm 0.21$ & $0.11-0.34$ & $0.21 \pm 0.05$ \\
\hline I & 132 & 44.4 & $3.4-5.7$ & $4.53 \pm 0.64$ & $0.23-2.17$ & $0.77 \pm 0.38$ \\
\hline II & 137 & 42.1 & $4.6-7.5$ & $6.31 \pm 0.59$ & $1.32-4.58$ & $2.34 \pm 0.74$ \\
\hline III & 32 & 9.8 & $6.9-8.4$ & $7.63 \pm 0.37$ & $2.91-6.82$ & $4.23 \pm 0.87$ \\
\hline$\Sigma$ & 347 & & $2.6-8.4$ & $5.53 \pm 1.12$ & $0.11-6.82$ & $1.83 \pm 1.23$ \\
\hline
\end{tabular}

Örneklenen bireylerin total boylarının 2.6 ile $8.4 \mathrm{~cm}$ arasında değişim gösterdiği belirlenmiş olup ortalama değer $5.53 \pm 1.12 \mathrm{~cm}$ olarak hesaplanmıştır Bireysel ağırlık değerleri ise $0.11-6.82 \mathrm{~g}$ arasında değişim 
göstermekte olup ortalama ağırlık $1.83 \pm 1.23 \mathrm{~g}$ şeklinde hesaplanmıştır. Total boy frekans değişimi dikkate alındığında normal dağılış sergilediği en yüksek frekansa sahip boy grubunun $5 \mathrm{~cm}$ boy grubu olduğu görülmektedir (Şekil 1).

Alburnus caeruleus türünde standart, çatal ve total boylar aralarında dönüşüm yapılabilmesi amacıyla aralarındaki ilişkiler $\quad \mathrm{CB}=\left(0.8621^{*} \mathrm{TL}\right)-0.4617$, $\mathrm{SB}=(0.877 * \mathrm{TL})-0.5605$ ve $\mathrm{TB}=(0.9958 * \mathrm{SB})-0.8174$ şeklinde formüle edilmiştir.

Alburnus caeruleus popülasyonu için boy-ağırlık ilişkisi $W=0.0063^{*} L^{3.2205}$ olarak belirlenmiştir (Şekil 2). İlişki sabitlerinden $b$ değeri için \%95 güvenirlilik aralığı 3.165-3.276 olarak hesaplanmıştır (Çizelge 2). $\mathrm{Bu}$ aralığın 3'ten fazla olması balıkların iyi beslendiğini ve ayrıca balığın pozitif allometrik büyüme özelliğini gösterdiği anlaşılmaktadır $(\mathrm{p}<0.05)$.
Alburnus caeruleus türü üzerinde tek çalışma İran'da Mousavi-Sabet ve ark. (2014) tarafından yapılmış olup boy-ağırlık ilişkisi $W=0.0082^{*} L^{3.072}$ olarak belirlenmiş olup büyümenin izometrik olduğu bildirilmiştir. Söz konusu çalışmada sadece 13 birey kullanılmış olup kullanilan bireylerinin total boylarınin $6.6-8.2 \mathrm{~cm}$ (7.26 \pm 0.65$)$ total ağırlık değerlerinin ise $2.83-5.40 \mathrm{~g}$ (3.71 1.08$)$ arasında değişim gösterdiği belirtilmiştir. $\mathrm{Bu}$ nedenle farklılığın sebebi gerek örnek sayısının az olmasından ve gerekse örneklerin belli boy grubuna sahip bireylerden oluşmasından kaynaklandığı açıkça görülmektedir.

Merzimen Çayı A. caeruleus popülasyonu için boyağırlık ilişkisi ve von Bertalanffy büyümesinin sabitleri, Munro'nun Fi Üssü ve Fulton'un kondüsyon faktörü değerleri Çizelge 2'de verilmiştir.

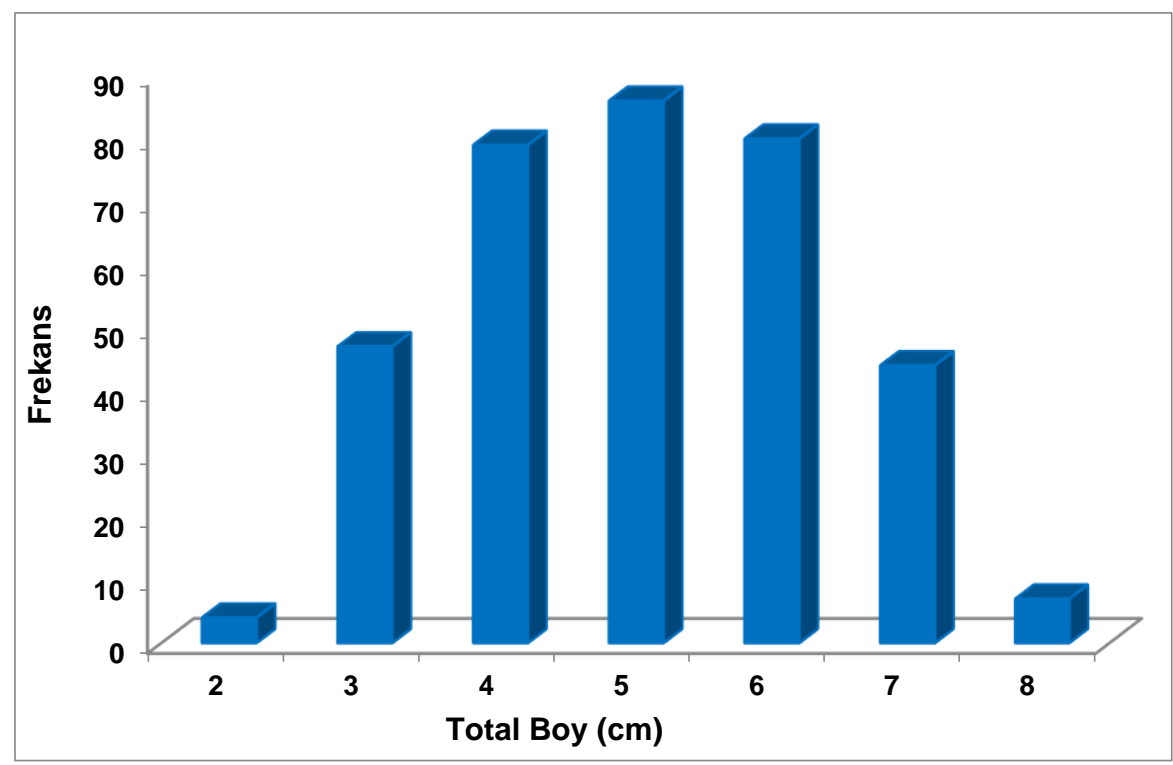

Şekil 1. Alburnus caeruleus popülasyonunda total boy ve frekans dağılımları

Figure 1. Total length and frequency distributions in Alburnus caeruleus population

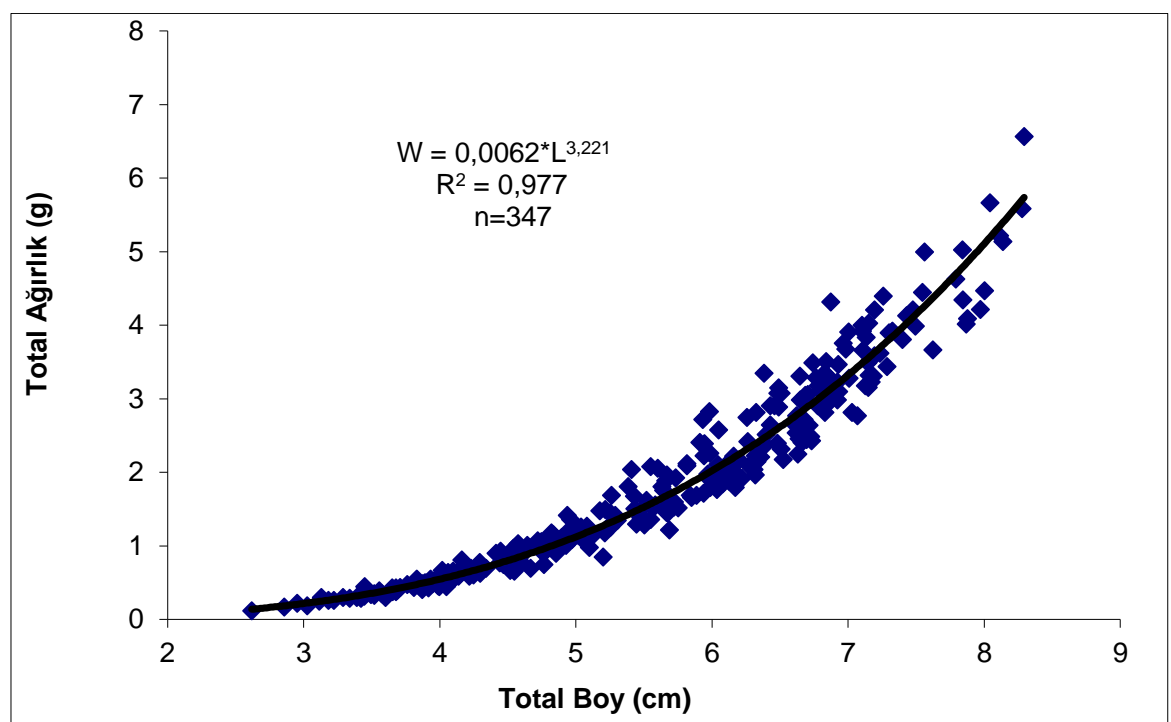

Şekil 2. Alburnus caeruleus popülasyonunda boy ve ağırlık ilişkileri

Figure 2. Lenght and weight relationships in Alburnus caeruleus population 
Çizelge 2. Merzimen Çayı Alburnus caeruleus popülasyonu için hesaplanmış popülasyon dinamiği parametreleri Table 2. Calculated population dynamics parameters for Merzimen stream Alburnus caeruleus population

\begin{tabular}{|c|c|c|c|c|c|c|c|c|c|}
\hline $\boldsymbol{a}$ & $\boldsymbol{b}$ & 95\% $\boldsymbol{C I}$ of $\boldsymbol{b}$ & $\boldsymbol{r}^{2}$ & $\boldsymbol{L}_{\infty}(\mathbf{c m})$ & $\boldsymbol{k}\left(\mathbf{y l l} \mathbf{l}^{-1}\right)$ & $\boldsymbol{t}_{0}(\mathrm{yll})$ & $\boldsymbol{W}_{\infty}(\mathbf{g})$ & $\boldsymbol{\Phi}^{\prime}$ & $\boldsymbol{K}$ \\
\hline 0.0062 & 3.221 & $3.165-3.276$ & 0.977 & 10.50 & 0.37 & -0.89 & 12.29 & 3.7 & $0.88 \pm 0.12$ \\
\hline
\end{tabular}

Alburnus caeruleus türü Merzimen Çayı popülasyonu için $k$ değeri 0.37 olarak belirlenmiş olup bu değer türün hızlı bir büyüme özelliği sergilediğine işaret etmektedir. Nitekim Froese ve ark. (2005) Brody'nin büyüme katsayısının $>0.3$ olduğu durumlarda hızlı büyüme özelliği sergilediği anlamına geldiğini ifade etmektedirler. Alburnus caeruleus küçük boylu ve kısa ömürlü bir tür olması nedeniyle böyle bir büyüme hızı beklenen bir durumdur (Froese ve ark., 2005). Toplam büyüme performans indeksi $(\Phi) \quad 3.7$ olarak belirlenmiştir.

Boy-ağırlık ilişki sabitlerinden a değeri ilgili türün incelenen periyot içindeki kondisyonunu ifade etmektedir. İncelenen popülasyon için a değerinin düşük olduğu düşünüldüğünce popülasyonun düşük bir kondisyona sahip olduğu ileri sürülebilir. Nitekim Fulton'un Kondisyon Faktörü değerinin de 1'in altında (0.88) olması kondisyonun düşük olduğuna işaret etmektedir. Kondüsyon faktörü değerinin karşılaştırılacağı başka bir çalışma olmaması nedeniyle düşük kondisyon değerinin habitat yada iklimsel koşullara bağlı olup olmadığı ile ilgili herhangi bir değerlendirme yapılması mümkün olmamıştır. Çünkü kondisyon türden türe değişiklik gösterdiği gibi, aynı tür içinde eşey, üreme dönemi, habitat özellikleri, beslenme ve iklimsel koşullara bağlı olarak değişiklik gösterebilmektedir (Avşar, 2005).

İncelenen popülasyon için doğal sebeplerle meydana gelen ölüm oranı (M) 0.55 ve balıkçılık sebebiyle oluşan ölüm oranı ise (F) çok daha düşük 0.24 olarak hesaplanmıştır. Bu değerler kullanılarak sömürülme oranının ise (E) 0.30 olduğu görülmüştür. Daha önce bu tür için ölüm oranı değerlerinin belirlenmemiş olması nedeniyle herhangi bir karşılaştırma yapılamamıştır. Ancak ekonomik öneme sahip olmayan bir tür olması nedeniyle ekseri olarak ölümlerin doğal nedenlerle meydana geliyor olması beklenen bir sonuçtur.

$\mathrm{Bu}$ çalışma ile daha önce ülkemizde üzerinde hiç çalışma yapılmamış bir tür olan $A$. caeruleus için bazı popülasyon dinamiği parametreleri belirlenmiştir. Daha önce 13 birey üzerinden sadece boy-ağırlık ilişkisinin belirlendiği düşünüldügünde (MousaviSabet ve ark., 2014) bu çalışmada türe ait popülasyon büyüme ve ölüm parametrelerinin en doğru şekilde belirlenmiş olduğu ileri sürülebilir.

\section{Araştırmacıların Katkı Oranı Beyan Özeti}

Yazarlar makaleye eşit oranda katkı sağlamış olduklarını beyan eder.

\section{Çıkar Çatışması Beyanı}

Makale yazarları aralarında herhangi bir çıkar çatışması olmadığını beyan ederler.

\section{KAYNAKLAR}

Avşar D 2005. Balıkçılık Biyolojisi ve Popülasyon Dinamiği. Nobel Kitapevi, Adana, 332s.

Beverton RJH, Holt SJ 1957. On the Dynamics of Exploited Fish Populations, Great Britain, Ministry of Agriculture, Fisheries, and Food, Fishery Investigations Series, 19, 533p.

Birecikligil S, Eagderi S, Roudbar AJ, Çiçek E 2017. Alburnoides recepi, a Junior Synonym of Alburnus caeruleus (Teleostei:Cyprinidae). Zootaxa, 4277(1): 129-136.

Coad BW 2010. Freshwater Fishes of Iraq. Pensoft Publishers, Sofia-Moscow. 294 pp.

Coad BW 2020. Freshwater Fishes of Iran. Revised: 20 September 2019, http://www.briancoad.com.

Çiçek E, Birecikligil S, Frickle R 2015. Freshwater fishes of Turkey; a Revised and Updated Annotated Checklist. Biharean Biologists. 9(2): 145-146.

Çiçek E, Fricke R, Sungur S, Eagderi S 2018. Endemic Freshwater Fishes of Turkey. FishTaxa, 3(4): 1-39.

Esmaeili HR, Sayyadzadeh G, Eagderi S, Abbasi K 2018. Checklist of Freshwater Fishes of Iran. FishTaxa 3(3): 1-195.

Freyhof J, Turan D 2019. Alburnus magnificus, a New Species of Bleak From the Orontes River Drainage (Teleostei:Leuciscidae). Zootaxa, 4559(2): 373-383.

Froese R, Palomares MLD, Pauly D 2005. Estimation of Life-History Key Facts. Version of 22 February 2005. https://www.fishbase.in/manual/key\%20facts.htm.

Geldiay R, Balık S 2007. Türkiye Tatlısu Balıkları. Ege Üniversitesi $\mathrm{Su}$ Ürünleri Fakültesi Yayınları No:46, V. Baskı, İzmir, 300s.

Kara C, Alp A 2016. Distribution of Fish Fauna in Adiyaman Region, Turkey, Yunus Araştırma Bülteni (3): 163-182.

Kaya C, Turan D, Ünlü E 2016. The Latest Status and Distribution of Fishes in Upper Tigris River and Two New Records for Turkish Freshwaters. Turkish Journal of Fisheries and Aquatic Sciences, 16: 545-562.

Kottelat M, Freyhof J 2007. Handbook of European freshwater fishes. Publications Kottelat, Cornol and Freyhof, Berlin. 646 pp.

Mousavi-Sabet H, Khataminejad S, Vatandoust S 2014. Length-Weight and Length-Length Relations of the Seven Endemic Alburnus Species (Actinopterygii: Cypriniformes: Cyprinidae) in Iran. Acta Ichthyologica Et Piscatoria, 44(2): 157-158. 
Pauly D 1980. On the Interrelationships Between Natural Mortality, Growth Parameters, and Mean Environmental Temperature in 175 Fish Stocks. Conseil International pour l'Exploration de la Mer, 39: 175-192.

Sarıhan E, Çiçek E, Toklu B 2007. Balık Biyolojisine Giriş. Nobel Kitapevi, Adana, 137s.

Sparre P, Venema SC 1998. Introduction to tropical Fish Stock Assessment. Part 1. Manuel. FAO Fisheries Technical Paper. No.306.1 Rev.2, Rome,
FAO. 407p.

Ünlü E, Bilgin FH 1987. A taxanomic study on the fish species in Balıklıgöl (Şanlıurfa). Journal of Aquatic Products, University of Istanbul, 1(1): 39-156.

Zareian H, Esmaeili HR, Nejad RZ, Vatandoust S 2015. Hemiculter leucisculus (Basilewsky, 1855) and Alburnus caeruleus Heckel, 1843: New Data on Their Distributions in Iran. Caspian J. Env. Sci., 13(1): 11-20. 